\title{
Hierarchical Analysis of Regional Cultural and Creative Product Demand Based on Fuzzy Kano Model
}

\author{
Shilin Zhong ${ }^{1}$, Jianhua Lyu, Yuting Chen, Huiru Yang, Xiaofang Guo and Ming Chen ${ }^{1,2^{*}}$ \\ ${ }^{1}$ Forestry College, Sichuan Agricultural University, Chengdu 611130, China \\ ${ }^{2}$ Key Laboratory of Wood Industry and Furniture Engineering, Sichuan Agricultural University, Chengdu 611130, China
}

\begin{abstract}
In order to accurately grasp consumers' demand for regional cultural and creative products, this paper introduced the fuzzy Kano model demand algorithm. Firstly, the initial requirements of cultural and creative products were divided into three levels, and the corresponding fuzzy Kano questionnaire was designed. Then, through questionnaire survey and matrix processing of its data, the category of demand items was clarified, and the priority calculation of demand items was carried out with the help of the betterworse coefficient. Finally, it is concluded that consumers' preference for regional cultural and creative products is mainly concentrated in the behaviour layer and reflective layer, which could provide direction for the design of regional cultural and creative products.
\end{abstract}

\section{Introduction}

Regional cultural and creative products are the means and results of regional cultural materialization and the powerful material carrier. Regional cultural products also play an extremely important role in the promotion of local culture. Cultural and creative products that gain consumer value and emotional recognition can bring regional culture into people's daily life, so that consumers can get psychological satisfaction and spiritual enjoyment. This paper analyses consumer demand information through the fuzzy Kano model to clarify consumer preference and provide a reference for regional cultural and creative product design.

\section{Principle of fuzzy Kano model}

The Kano model is mainly used to analyse consumer needs and has a guiding role in the innovative design of products. But in the traditional Kano model questionnaire, consumers' uncertain thinking is often ignored. In response to this situation, Zadeh proposed a fuzzy Kano model, which uses interval fuzzy numbers instead of deterministic values 0 and 1 [1]. Consumers can assign an arbitrary value between $[0,1]$ according to their own situation, and the sum of the assignments is 1 (Table 1). Due to the diversity of demand elements of cultural and creative products, this paper adopts the fuzzy Kano model to grasp the real thoughts of consumers.

The Kano model divides product quality elements into five categories [2] (Figure 1). The three main tools for Kano model analysis are the Kano questionnaire, the kano evaluation form, and the kano survey results table [3].

Table 1. Fuzzy Kano model questionnaire

\begin{tabular}{llllll}
\hline Demand factors & Satisfied & Reasonable & Indifferent & Acceptable & Dissatisfied \\
\hline Realized & 0.7 & 0.2 & 0.1 & & \\
Not Realized & & & & 0.4 & 0.6 \\
\hline
\end{tabular}

\footnotetext{
*Corresponding author e-mail: chenming@sicau.edu.cn
} 


\begin{abstract}
Customer satisfaction
Characterization of fully

\section{Analysis of regional cultural and creative products and extraction of demand information}

\subsection{The current situation of regional cultural and creative products}

Due to the strong support of the state for cultural and creative industry, more and more regions have increased the investment in cultural and creative industry to enhance the soft power of culture [4]. However, most of the market a product lack of regional cultural characteristics, homogenization is serious. They do not achieve the combination of culture and design, can't meet the cultural psychological needs of consumers.

Charm quality factors (A) Unary quality factor $(\mathrm{O})$

Irrelevant quality elements (I) $\rightarrow$ Inadequate representation Essential quality elements(M)

Inverse quality elements(R)

Consumer dissatisfaction

Figure 1. Kano model can be clarified, which can provide a reference for the design of regional cultural and creative products.

\subsection{Classification of consumer initial demand information}

Demand analysis can provide the basis for design. In order to fully explore consumer demand, this paper adopts the methods of inquiry and survey, literature summary and so on to obtain the information of consumers' initial demand for regional cultural and creative products. Combined with the three-level theory of emotional design [5], the demand elements were classified and sorted according to the instinct layer, behavior layer and reflection layer, and the demand evaluation indexes in table 2 were obtained.
\end{abstract} Through the analysis of consumer demand information by the fuzzy Kano model, the preference of consumers

Table 2. Initial requirements evaluation item table

\begin{tabular}{llll}
\hline The target layer & Basic layer & Level 1 indicator & Level 2 indicator \\
\hline & Instinct layer & Modeling & Use the shape of traditional utensils \\
& & Color & Use local Colors \\
& & Material & Use regional materials \\
& & Pattern & Use local patterns \\
& Package & $\begin{array}{l}\text { The packing has regional } \\
\text { characteristics }\end{array}$ \\
\cline { 2 - 4 } $\begin{array}{l}\text { Cultural and creative } \\
\text { product design }\end{array}$ & Behavior layer & Function & Practical \\
& & Process & Characteristic craftsmanship \\
\cline { 2 - 4 } & Reflective layer & Experience & Contains historical culture \\
& & Cultural trait & Reflect regional culture \\
& & Emotional & Commemorative Significance \\
& & & Emotional resonance \\
& & Story & Contains allusions and legends \\
& & Attraction & Be interesting \\
& & & Be creative \\
\hline
\end{tabular}




\section{Demand information processing of cultural and creative products based on Fuzzy Kano Model}

\subsection{Fuzzy Kano questionnaire design and data collection}

The 14 level-2 indicators in table 3 were taken as the demand elements of regional cultural and creative products, and the fuzzy Kano questionnaire was designed (table 3). Offer five options: "satisfied," "reasonable," "indifferent," "acceptable," and "dissatisfied." Through questionnaire survey, consumer demand data is obtained. Analyse and sort the data, and then classify the requirements according to the Kano evaluation table (table 4) [6]. A total of 120 questionnaires were distributed and 116 were recovered, among which 3 answered questions. The true recovery rate was $94.2 \%$, which could guarantee the credibility of data processing.

Table 3. Fuzzy Kano model questionnaire

\begin{tabular}{|c|c|c|c|c|c|c|c|}
\hline number & $\begin{array}{l}\text { Demand } \\
\text { element }\end{array}$ & & Satisfied & Reasonable & Indifferent & Acceptable & Dissatisfied \\
\hline $\mathbf{e}_{1}$ & $\begin{array}{l}\text { Use the } \\
\text { shape of } \\
\text { traditional } \\
\text { utensils }\end{array}$ & $\begin{array}{l}\text { Realized } \\
\text { Not } \\
\text { Realized }\end{array}$ & 0.4 & 0.5 & $\begin{array}{l}0.1 \\
0.2\end{array}$ & 0.6 & 0.2 \\
\hline $\mathbf{e}_{2}$ & $\begin{array}{l}\text { Use local } \\
\text { Colors }\end{array}$ & $\begin{array}{l}\text { Realized } \\
\text { Not } \\
\text { Realized }\end{array}$ & 0.3 & 0.3 & $\begin{array}{l}0.4 \\
0.2\end{array}$ & 0.7 & 0.1 \\
\hline $\mathbf{e}_{3}$ & $\begin{array}{l}\text { Use } \\
\text { regional } \\
\text { materials }\end{array}$ & $\begin{array}{l}\text { Realized } \\
\text { Not } \\
\text { Realized }\end{array}$ & 0.1 & 0.2 & $\begin{array}{l}0.7 \\
0.6\end{array}$ & 0.2 & 0.2 \\
\hline
\end{tabular}

Table 4. Kano Evaluation Form

\begin{tabular}{ccccccc}
\hline \multirow{2}{*}{ Product demand } & \multicolumn{5}{c}{ Not Realized } \\
\cline { 2 - 6 } & Satisfied & Satisfied & Reasonable & Indifferent & Acceptable & Dissatisfied \\
\hline \multirow{3}{*}{ Realized } & Deserved & $\mathrm{R}$ & $\mathrm{A}$ & $\mathrm{A}$ & $\mathrm{A}$ & $\mathrm{O}$ \\
& Indifferent & $\mathrm{R}$ & $\mathrm{I}$ & $\mathrm{I}$ & $\mathrm{I}$ & $\mathrm{M}$ \\
& Indifferent & $\mathrm{R}$ & $\mathrm{I}$ & $\mathrm{I}$ & $\mathrm{I}$ & $\mathrm{M}$ \\
& Dissatisfied & $\mathrm{R}$ & $\mathrm{R}$ & $\mathrm{I}$ & $\mathrm{I}$ & $\mathrm{M}$ \\
\hline
\end{tabular}

\subsection{Construct fuzzy matrix to determine membership degree}

User demand data is obtained by fuzzy Kano model questionnaire, and the data processing steps are as follows [7]:

$$
S=X^{T} Y=\left[\begin{array}{ll}
0 & 0 \\
0 & 0 \\
0 & 0 \\
0 & 0 \\
0 & 0
\end{array}\right.
$$

(2) Calculate membership vector. Mapping the elements in matrix s to Kano model evaluation table (Table 4) determines the corresponding demand type for the values in the matrix. For example, the charm quality element (a) in matrix s is S12, S13 and S14, $(12,13$ and 14 represent the first row, the second column, the first row, the third column, and the first row, the fourth column), then $\mathrm{S}_{\mathrm{A}}=0+0.08+0.24=$ 0.32 , and so on, its membership vector can be obtained:
(1) Establish fuzzy matrix. Take E1 index in Table 3 as an example. Then the matrix to realize this element is $X=\left[\begin{array}{lllll}0.4 & 0.5 & 0.1 & 0 & 0\end{array}\right]$, and the matrix not to realize this element is $\mathrm{Y}=$ $\left[\begin{array}{lllll}0 & 0 & 0.2 & 0.6 & 0.2\end{array}\right]$. The generated interaction matrix is:

$$
\begin{aligned}
& \begin{array}{lll}
0.08 & 0.24 & 0.08
\end{array} \\
& \begin{array}{lll}
0.10 & 0.30 & 0.10 \\
0.02 & 0.06 & 0.02
\end{array} \\
& \begin{array}{ccc}
0.02 & 0.06 & 0.02 \\
0 & 0 & 0
\end{array} \\
& \begin{array}{lll}
0 & 0 & 0
\end{array} \\
& T_{e 1}=\left(\frac{0.18}{S_{M}}, \frac{0.08}{S_{O}}, \frac{0.32}{S_{A}}, \frac{0.48}{S_{I}}, \frac{0}{S_{R}}\right)
\end{aligned}
$$

(3) Introduce a confidence level $\alpha$. In order to make the values more accurate, it is necessary to introduce a confidence level $\alpha(\alpha=0.4)$ to filter the data in $\mathrm{T}_{\mathrm{e} 1}$. When an element in $\mathrm{T} \geq \alpha$, the element takes 1 and vice versa. After screening, $\mathrm{T}_{\mathrm{e} 1}=(0,0,0,1,0)$ is obtained, and the demand type corresponding to el is the indifferent quality factor (I). 


\subsection{Classification of demand factors for regional cultural and creative products}

Repeat the above calculation process for each questionnaire. And take the result with the most occurrence times as the final demand type of this index. Taking $\mathrm{e}_{1}$ as an example. Through statistics, 53 people believed that "cultural and creative products follow traditional utensil modelling" was the indifferent quality factor (I), with the largest proportion, so it was determined to be the indifferent quality factor. The statistical results of the whole questionnaire are shown in table 5 .

Table 5. Regional cultural and creative product demand factor analysis results

\begin{tabular}{|c|c|c|c|c|c|c|c|c|c|}
\hline \multirow{2}{*}{ Basic layer } & \multirow{2}{*}{ Number } & \multirow{2}{*}{ Demand element } & \multicolumn{6}{|c|}{ Statistical quantity } & \multirow{2}{*}{$\begin{array}{c}\text { Categor } \\
\mathrm{y}\end{array}$} \\
\hline & & & $\mathrm{M}$ & $\mathrm{O}$ & A & I & $\mathrm{R}$ & $\mathrm{Q}$ & \\
\hline \multirow{5}{*}{ Instinct layer } & $\mathrm{e}_{1}$ & $\begin{array}{l}\text { Use the shape of traditional } \\
\text { utensils }\end{array}$ & 13 & $\begin{array}{l}1 \\
8\end{array}$ & $\begin{array}{l}2 \\
5\end{array}$ & $\begin{array}{l}5 \\
7\end{array}$ & 0 & 0 & I \\
\hline & $e_{2}$ & Use local Colors & 7 & 11 & $\begin{array}{l}2 \\
6\end{array}$ & $\begin{array}{l}4 \\
9\end{array}$ & 0 & 0 & I \\
\hline & $e_{3}$ & Use regional materials & 10 & 9 & $\begin{array}{l}3 \\
1\end{array}$ & $\begin{array}{l}6 \\
3\end{array}$ & 0 & 0 & I \\
\hline & $\mathrm{e}_{4}$ & Use local patterns & 7 & $\begin{array}{l}1 \\
6\end{array}$ & $\begin{array}{l}7 \\
2\end{array}$ & $\begin{array}{l}1 \\
8\end{array}$ & 0 & 0 & A \\
\hline & $\mathrm{e}_{5}$ & $\begin{array}{l}\text { The packing has regional } \\
\text { characteristics }\end{array}$ & 9 & 8 & $\begin{array}{l}3 \\
2\end{array}$ & $\begin{array}{l}5 \\
4\end{array}$ & 0 & 0 & I \\
\hline \multirow[b]{2}{*}{ Behavior layer } & $\mathrm{e}_{6}$ & Practical & 28 & $\begin{array}{l}2 \\
1\end{array}$ & $\begin{array}{l}5 \\
5\end{array}$ & 9 & 0 & 0 & A \\
\hline & $\mathrm{e}_{7}$ & Characteristic craftsmanship & 12 & 8 & $\begin{array}{l}5 \\
9\end{array}$ & $\begin{array}{l}3 \\
4\end{array}$ & 0 & 0 & A \\
\hline \multirow{7}{*}{ Reflective layer } & $\mathrm{e}_{8}$ & Contains historical culture & 20 & $\begin{array}{l}1 \\
7\end{array}$ & $\begin{array}{l}6 \\
5\end{array}$ & 11 & 0 & 0 & A \\
\hline & $\mathrm{e}_{9}$ & Reflect regional culture & 33 & $\begin{array}{l}6 \\
3\end{array}$ & $\begin{array}{l}1 \\
4\end{array}$ & 3 & 0 & 0 & $\mathrm{O}$ \\
\hline & $\mathrm{e}_{10}$ & Commemorative Significance & 19 & $\begin{array}{l}5 \\
9\end{array}$ & 7 & $\begin{array}{l}2 \\
8\end{array}$ & 0 & 0 & $\mathrm{O}$ \\
\hline & $e_{11}$ & Emotional resonance & 16 & $\begin{array}{l}1 \\
9\end{array}$ & $\begin{array}{l}5 \\
7\end{array}$ & $\begin{array}{l}2 \\
1\end{array}$ & 0 & 0 & A \\
\hline & $\mathrm{e}_{12}$ & Contains allusions and legends & 4 & $\begin{array}{l}2 \\
1\end{array}$ & $\begin{array}{l}4 \\
8\end{array}$ & $\begin{array}{l}4 \\
0\end{array}$ & 0 & 0 & A \\
\hline & $\mathrm{e}_{13}$ & Be interesting & 8 & $\begin{array}{l}2 \\
1\end{array}$ & $\begin{array}{l}5 \\
3\end{array}$ & $\begin{array}{l}3 \\
1\end{array}$ & 0 & 0 & A \\
\hline & $\mathrm{e}_{14}$ & Be creative & 22 & $\begin{array}{l}2 \\
5\end{array}$ & $\begin{array}{l}5 \\
2\end{array}$ & $\begin{array}{l}1 \\
4\end{array}$ & 0 & 0 & A \\
\hline
\end{tabular}

\subsection{Priority analysis of demand factors}

After determining the demand type, to further divide the demand levels, the better-worse coefficient is used to determine the priority degree [8]. Better (SI) means the satisfaction after increasing a certain factor; Worse (DSI) indicates the degree of dissatisfaction after removing a factor. Its calculation formula is as follows:

$$
\begin{gathered}
S I=(A+O) /(A+O+M+I) \\
D S I=(O+M) /(A+O+M+I) \times(-1)
\end{gathered}
$$

According to the statistical result of the demand category, the SI and DIS values of each element can be calculated. The calculation results are shown in Table 6.

Table 6. SI and DSI data sheets

\begin{tabular}{cccccc}
\hline Number & SI & DSI & Number & SI & DSI \\
\hline $\mathrm{e}_{1}$ & 0.32 & -0.16 & $\mathrm{e}_{8}$ & 0.73 & -0.33 \\
$\mathrm{e}_{2}$ & 0.40 & -0.19 & $\mathrm{e}_{9}$ & 0.68 & -0.85 \\
$\mathrm{e}_{3}$ & 0.35 & -0.17 & $\mathrm{e}_{10}$ & 0.58 & -0.69 \\
$\mathrm{e}_{4}$ & 0.78 & -0.20 & $\mathrm{e}_{11}$ & 0.67 & -0.31 \\
$\mathrm{e}_{5}$ & 0.39 & -0.17 & $\mathrm{e}_{12}$ & 0.61 & -0.22 \\
$\mathrm{e}_{6}$ & 0.67 & -0.43 & $\mathrm{e}_{13}$ & 0.65 & -0.26 \\
$\mathrm{e}_{7}$ & 0.59 & -0.18 & $\mathrm{e}_{14}$ & 0.68 & -0.42 \\
\hline
\end{tabular}




\section{Consumer preference analysis of regional cultural and creative products}

According to the results of Table 5, among the 14 demand elements, the two demand elements belonging to the unary quality factor are: " reflect regional culture " and "commemorative significance"; the eight demand elements belonging to the glamour quality factor are: " use local patterns, "practical", "characteristic craftsmanship", " contains historical culture ", " Emotional resonance ", " contains allusions and legends ", " be interesting ", "be creative"; the four demand elements belonging to the irrelevant quality elements are: "use the shape of traditional utensils", " use local colors ", " use regional materials ", " The packing has regional characteristics ". The results show that consumers pay more attention to the demand elements of the behavioral and reflective layers than the formal needs of the instinct.

\subsection{Preference analysis of instinct layer}

Among the five demand factors of the instinct layer, only "use regional patterns" belongs to the charm quality factor, while the rest belong to the irrelevant quality elements, which indicates that consumers have a high degree of tolerance for the index of the instinct layer. In terms of appearance, consumers pay less attention to whether the product uses the shape, color and materials of local traditional utensils. Consumer's interest point mainly concentrates on the local characteristic ornamentation. On the premise that other basic aesthetic needs are satisfied, consumers are more inclined to buy cultural and creative products with local characteristics.

\subsection{Behavioral layer preference analysis}

Whether the demand elements of the behavior layer are satisfied has a great influence on the satisfaction of consumers. The practicality and production process of cultural and creative products are both charm quality factors, which indicates that both of them are within the range of factors for consumers to consider whether to buy products or not. Practical cultural and creative products made by local special technology can be welcomed by consumers. However, the absolute value of SI and DSI of "characteristic craftsmanship" is relatively low, indicating that compared with "practical", this factor has a small impact on consumer satisfaction. If it is in conflict with the economy, the modern manufacturing method can be considered.

\subsection{Reflective layer preference analysis}

The demand elements of reflective layer are unitary quality elements and charm quality elements, which are the focus of consumers. Among the charm quality factors, the highest SI value is "contains historical culture". But at the same time, the "creative" DSI is -0.42 , whose absolute value is higher than other reflective requirements. Therefore, regional cultural and creative products with historical background and creativity are easy to be favoured by consumers. Among the unitary quality factors, the absolute SI and DSI of "reflect regional culture" are both the highest. Therefore, this demand factor is the core of regional cultural and creative product design, and cultural and creative products with this factor are most recognized by consumers. The integration of regional culture and cultural and creative product design can enhance the highlight of design.

\section{Conclusion}

In this paper, the fuzzy Kano model is constructed based on the current situation that the regional cultural and creative products can not effectively meet the needs of consumers. The initial demand information is hierarchically divided to provide direction for the design of regional cultural and creative products. Through the analysis of the survey data of the questionnaire, the quality categories corresponding to each demand element are clarified. Based on this, the demand item priority analysis is carried out. The results show that the focus of consumers on regional cultural and creative products is mainly reflected in the reflection layer, followed by the behavior layer. This shows that regional cultural and creative products with practicality and cultural connotation are more popular with consumers. Regional and creative products that combine practicality and spirituality can not only enhance the design highlights, but also promote the spread of regional culture.

\section{Acknowledgments}

The authors are grateful for the support of the Ministry of Education Humanities and Social Sciences Research Project of China (Grant No. 19YJC760009), the Project of Modern Design and Culture Research Centre, Sichuan Key Research Base of Philosophy and Social Sciences (Grant No. MD18Z002) and Research Project of Double Support Program for Art Special Project in Sichuan Agricultural University of 2019.

\section{References}

1. Meng Qingliang, $\mathrm{He}$ Lin. Quality attribute classification method based on fuzzy Kano model and its application[J]. Industrial Engineering, 2013(6): 121-125.

2. ATLASON R S, STEFANSSON A S, WIETZ M, et al. A rapid kano-based approach to identify optimal user segments [J]. Research in Engineering Design, 2018, 29(3): 459-467

3. Chen Wei, Ning Meng, Xu Xiangkai, et al. Design of Household Shift Auxiliary Equipment Based on Kano Model[J]. Mechanical Design, 2016, 33(12): 109-114. 
4. Zhang Wei. The Creative Design Strategy of Wenchuang Products from the Perspective of Regional Culture [J]. Design, 2018, 19: 54-56.

5. Donald Norman. Emotional Design $[\mathrm{M}] . \mathrm{Fu}$ Qiufang, Cheng Jinsan, translated. Beijing: Publishing House of Electronics Industry, 2005.

6. Liu Songyan. Design of child safety seat based on fuzzy Kano model [D]. Harbin: Harbin University of Science and Technology, 2019.

7. Lin Xiaofang, Wang Haichuan, Cheng Lin. Judgment and importance adjustment of chain distribution service quality demand attribute based on fuzzy Kano model[J].Logistics Technology,2016,10:1-6+19.

8. Wang Qian, Hou Shuikun, Pei Chenge. Analysis of demand items of Henan tourist souvenirs based on KANO model [J]. Industrial Design, 2019, 05: 80-81. 